\title{
Structure of nematocysts isolated from the fire corals Millepora alcicornis and Millepora complanata (Cnidaria: Hydrozoa)
}

García-Arredondo A (1, 2), Rojas A (1), Iglesias-Prieto R (3), Zepeda-Rodriguez A (4), Palma-Tirado L (5)

(1) Laboratory of Chemical and Pharmacological Natural Products Research, School of Chemistry, Autonomous University of Querétaro, Querétaro, Mexico; (2) Postgraduate Program in Marine Sciences and Limnology, National Autonomous University of Mexico, Mexico City, Mexico; (3) Puerto Morelos Academic Unit, Institute of Marine Sciences and Limnology, National Autonomous University of Mexico, Cancun, Mexico; (4) Department of Cell and Tissue Physiology, School of Medicine, National Autonomous University of Mexico, Mexico City, Mexico; (5) Microscopy Unit, Institute of Neurobiology, National Autonomous University of Mexico, Querétaro, Mexico.

\begin{abstract}
Structural characteristics of discharged and undischarged nematocysts from the hydrozoans Millepora alcicornis and Millepora complanata, two fire corals collected in the Mexican Caribbean, were examined using transmission electron, scanning and light microscopy. In this study, we report for the first time images of the nematocysts found in these Mexican Caribbean venomous species. Two types of nematocysts were observed in both species, the more abundant identified as macrobasic mastigophore and the other a stenotele type. Macrobasic mastigophores were present in medium and large size classes while stenoteles appeared in only one size.
\end{abstract}

Key words: hydrocoral, nematocysts, microscopy images, macrobasic mastigophore, stenotele.

\section{INTRODUCTION}

Hydrozoan cnidarians of the genus Millepora are commonly denominated fire corals since contact with them immediately causes burning pain, erythema and pustule formation on human skin (1-3). These hydrocorals are able to induce their damaging effects due to the presence of nematocysts, the characteristic stinging organelles used by all cnidarians for defense and capturing prey (4). Several studies have shown that the venom contained in the nematocysts from Millepora species display lethal, hemolytic, dermonecrotic, and antigenic properties (5-10).

Each nematocyst is contained in a cnidocyte (nematocyte), the specialized cnidarian cell named after the phylum Cnidaria. The nematocyst structure consists of a globular or egg-shape capsule, made up mainly of mini-collagens and the glycoprotein NOWA, which has an apical aperture closed by a cover (operculum) and an inverted long spiny tubule inside (11). The nematocyst capsule wall resists an extreme intracapsular pressure of 150 bar, and upon receipt of an appropriate mechanical and/or chemical stimulus, the internal pressure is released $(12,13)$. This causes the eversion of the spiny tubule through the operculum and injects the venom into the prey. The mechanism of discharge of the nematocyst is a very rapid and explosive event that occurs over a period of less than 3 milliseconds. For this reason, this mechanism is considered one of the fastest processes in biology (14). Moreover, on account of their intricate structure, nematocysts were considered by Mariscal (15) to be one of the most complex intracellular secretion products known.

The most widely used classification of the variable morphology presented by nematocysts is derived from the work of Weill $(16,17)$. To date, more than 30 particular types of nematocysts have been identified based on Weill's work, which consisted of observations under a light 
microscope, primarily of the discharged tubule and its spine pattern $(15,18)$. Nematocyst morphology is potentially of taxonomic importance. For example, of the 25 types recognized by Mariscal (15), 17 occur exclusively in Hydrozoa, and two occur exclusively in Anthozoa. The morphology and dimensions of the nematocysts are now considered essential to any taxonomic description or redescription of a cnidarian species (18). Furthermore, the appearance of the inverted tubule, coiled inside the capsule, also constitutes a distinct diagnostic characteristic (19). At present, very little is known about the nematocysts found in the Caribbean Millepora species. Therefore, by employing different microscopy techniques, the present study was undertaken to identify, examine and compare the structure of the nematocysts isolated from two hydrocorals collected in the Mexican Caribbean: Millepora complanata, a plate-like fire coral (Figure 1 - A); and Millepora alcicornis, a branching fire coral (Figure $1-\mathrm{B}$ ).

\section{MATERIALS AND METHODS}

\section{Specimen Collection and Isolation of Nematocists}

Fragments of $M$. complanata and $M$. alcicornis were collected by scuba diving, to depths of 4 to
$10 \mathrm{~m}$, in the area known as "La Bocana Chica", located within the National Reef Park (Parque Nacional Arrecife) of Puerto Morelos (Quintana Roo, México), in November 2008. Fragments were frozen immediately after collection and stored at $-70^{\circ} \mathrm{C}$.

Nematocysts were released from the calcareous exoskeleton as described by Radwan (9) as follows: hydrocoral fragments were stirred in acidic saline solution $(0.02 \mathrm{M} \mathrm{HCl}$ in $0.15 \mathrm{M} \mathrm{NaCl} ; \mathrm{pH} 7)$ for 24 hours at $4^{\circ} \mathrm{C}$. Afterward, exoskeletons fragments were removed and the resultant suspension was filtered using a metal screen $(0.5 \mathrm{~mm}$ pore size). The filtrate was centrifuged for two minutes at $200 \mathrm{rpm}(5 \mathrm{~g})$, and the supernatant obtained was removed by pipette and discarded. The pellet, containing a mixture of nematocysts and zooxanthellae, was placed in freshly filtered sea water and re-centrifuged for two minutes at 200 rpm. The supernatant obtained was removed and discarded. This process was repeated one more time and the resulting pellet was used for microscopic examination.

\section{Microscopic Examination}

Pellets containing nematocysts were first observed directly through light microscopy (LM). For more detailed observations, pellets were studied by scanning and transmission electron microscopy (SEM and TEM). For TEM and SEM
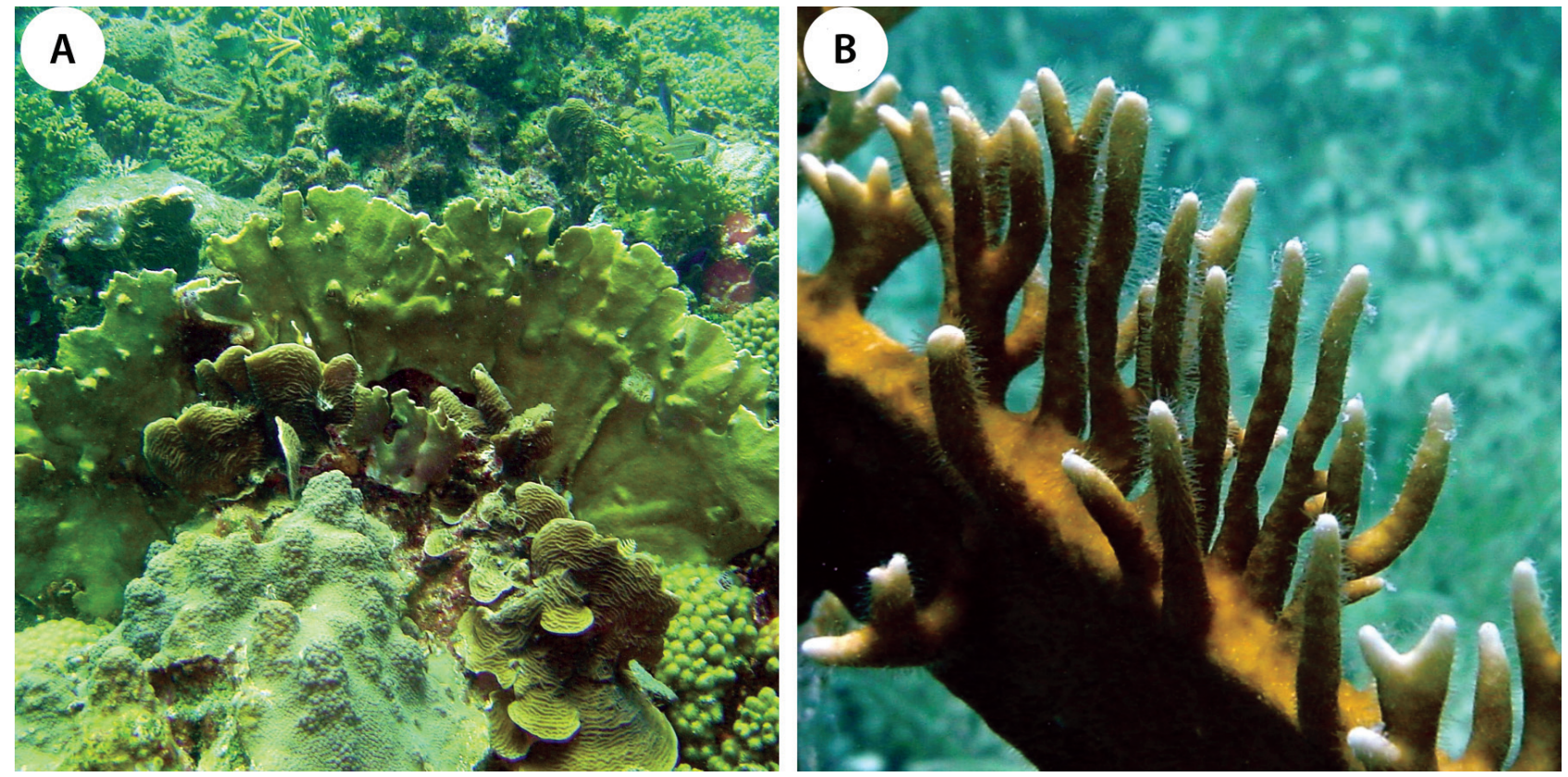

Figure 1. Underwater images of the two Mexican Caribbean fire corals: (A) Millepora complanata and (B) Millepora alcicornis. 
examinations, pellets containing nematocysts were fixed in filtered sea water containing 3\% glutaraldehyde and $0.1 \mathrm{M}$ sodium cacodylate, postfixed in $2 \% \mathrm{OsO}_{4}$ in cacodylate buffer, and dehydrated in an ethanol series.

For TEM examinations, pellets were embedded in Epon (epoxic resine), the blocks obtained were sectioned into thin slices $(60 \mathrm{~nm})$ in an ultramicrotome (Mtx RMC ${ }^{\oplus}$, Boeckler Instruments, USA) and contrasted with uranyl acetate and lead citrate. These sections were observed in a transmission electron microscope (JEM $1010^{\circledR}$, Jeol, USA) operated at $80 \mathrm{kV}$. For SEM examination, the nematocysts were dried in a critical-point-dryer apparatus (Polaron E5000 ${ }^{\circ}$, Quorum Technologies, UK), covered with carbon in an evaporator (JEE4X ${ }^{\circledR}$, Jeol, USA) and with a thin sheet of gold in an ion sputterer (Polaron 11-HD ${ }^{\oplus}$, Quorum Technologies, UK), and finally observed with a scanning electron microscope (DSM $950^{\circ}$, Zeiss International) at an accelerating voltage of 20 to $25 \mathrm{kV}$.

\section{RESULTS AND DISCUSSION}

In this study, two types of nematocysts were observed in both Caribbean Millepora species. These nematocysts were identified as stenoteles and macrobasic mastigosphores according to Weill's classification $(16,17)$. Measurements of the capsule size of the nematocysts, made from the SEM photographs, showed that in both species the macrobasic mastigophores were present in medium $(10.6-13.0 \times 18.1-21.6 \mu \mathrm{m})$ and large $(17.5-21.8 \times 25.0-33.1 \mu \mathrm{m})$ size classes, while stenoteles were present in only one size (10.5 $15.6 \times 18.7-25.0 \mu \mathrm{m})$.

Stenoteles are penetrating nematocysts limited to the class Hydrozoa and are found mostly in hydras $(20,21)$. In this study, we found the presence of few stenoteles in both Millepora species. Calder (22) reported that the gastrozooids of M. alcicornis, collected in Bermuda, contained stenoteles of small (5.7-6.6 x 8.3-8.9 $\mu \mathrm{m})$, medium (12.9-14.2 x 15.9-17.6 $\mu \mathrm{m})$ and large $(15.9-18.7 \times 21.6-24.7 \mu \mathrm{m})$ sizes, whereas the dactylozooids only contained small stenoteles (5.9-6.5 x 8.3-8.6 $\mu \mathrm{m})$. The capsule of the undischarged form of this nematocyst type has a characteristic lime shape with pointed ends (Figure 1-A, B), one of these ends consists of an aperture closed by a cover known as an operculum, whose diameter is approximately $4.5 \mu \mathrm{m}$ while the other extreme has a diameter of approximately 2 $\mu \mathrm{m}$ (Figure 1 - B).

The structure of the discharged form of the stenoteles presents an everted broad shaft with a diameter of about $5.5 \mu \mathrm{m}$, and is slightly wider at its base. The basal part of the shaft is unarmed, but at the distal portion there are three large spines (called stylets) followed by a short contracted section armed with three helically coiled bands of spines and a thin tubule posterior to the shaft (Figure $2-\mathrm{C}$ to $\mathrm{E}$ ). The LM image of the undischarged form of this nematocyst type showed the inverted shaft as a straight shape, folded back within the capsule, with the styletes and the small spines pointing away from the operculum (Figure $2-\mathrm{A}$ ). Figure $2-\mathrm{F}$ is a TEM image of an undischarged stenotele at the level of the stylets, close to the operculum, showing the inverted shaft in the center of the capsule.

The most abundant nematocyst type found in both Millepora species was the macrobasic mastigophore. The structure of the undischarged form consists of an egg-shaped capsule with an inverted tubule coiled with an amorphous arrangement, which can be observed in the LM photographs (Figure 3 - A). The operculum, located in the apical part of the capsule, has a diameter of approximately $2.5 \mu \mathrm{m}$ in both large and medium size classes (Figure $3-\mathrm{B}$ ). In the discharged form of this nematocyst type one observes that the everted tubule is armed with three helically coiled bands of spines extended throughout the length of the tubule (Figure $3-\mathrm{C}$ to F). Figure 3 - E shows a macrobasic mastigophore with the everted tubule completely extended; this tubule has a diameter of $1.6 \mu \mathrm{m}$ while the shaft, an enlarged portion in the middle of the tubule, has a diameter of $2.3 \mu \mathrm{m}$.

Interestingly, Grajales and Sánchez (23) found in SEM images a discharged macrobasic mastigophore of M. alcicornis from the Colombian Caribbean with a bifurcation at the end of the tubule. However, in the present study we did not find any nematocysts with this characteristic. In TEM images of the undischarged form (Figure 4 ), the arrangement of spines on the inverted shaft shows a tripartite symmetry; portions of the inverted tubule are seen in these images.

Measurements on TEM photographs show that the thickness of the stenotele capsule wall is about $1 \mu \mathrm{m}$, whereas the macrobasic mastigophores has a thickness of approximately $1.5 \mu \mathrm{m}$. In these 

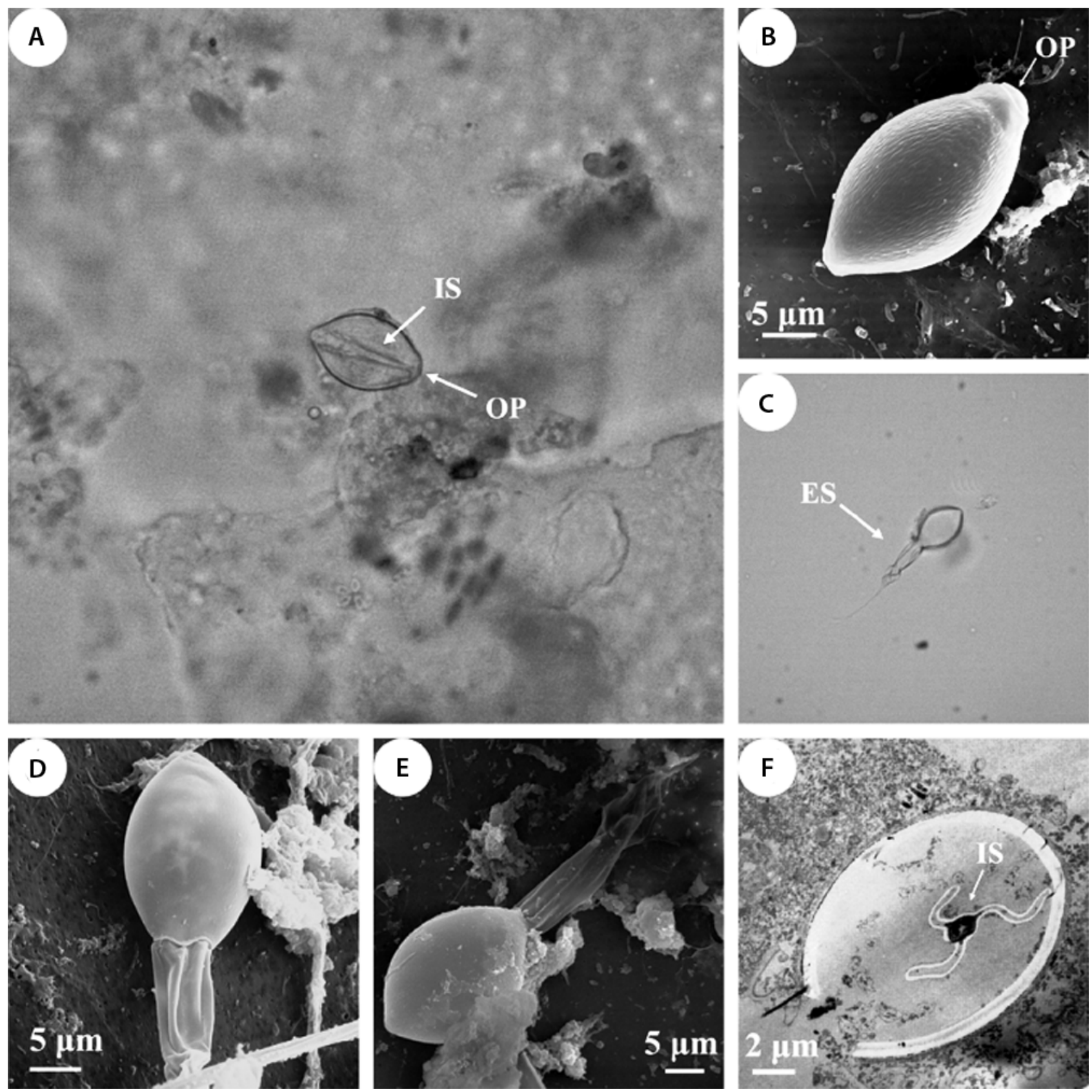

Figure 2. (A) LM image of an undischarged stenotele isolated from Millepora complanata showing the operculum (OP) and the inverted shaft (IS), magnification 400x. (B) SEM image of an undischarged stenotele isolated from M. alcicornis. (C) LM image of a discharged stenotele isolated from M. complanata, showing the everted shaft (ES), magnification 400x. (D) SEM image of a discharged stenotele isolated from M. alcicornis. (E) SEM image of a discharged stenotele isolated from M. complanata. (F) TEM image of an undischarged stenotele isolated from $M$. complanata through the stylets section of the IS.

TEM images one can distinguish two layers in the capsule wall of both nematocyst types, a darker inner layer and an outer layer. It has been described previously that the nematocyst capsule wall is composed of two distinct layers, glycoprotein NOWA is associated with the outer layer whereas the inner layer is thought to be a dense and elastic layer composed mainly of mini-collagen (24).
The macrobasic mastigophore is a nematocyst type found exclusively in Millepora species and actually constitutes one reason for placing it in a separate suborder (21). In this study, we found that this type of nematocyst is the most abundant in the Caribbean species M. alcicornis and M. complanata. Radwan (9) observed that two species collected in the Red Sea, $M$. 

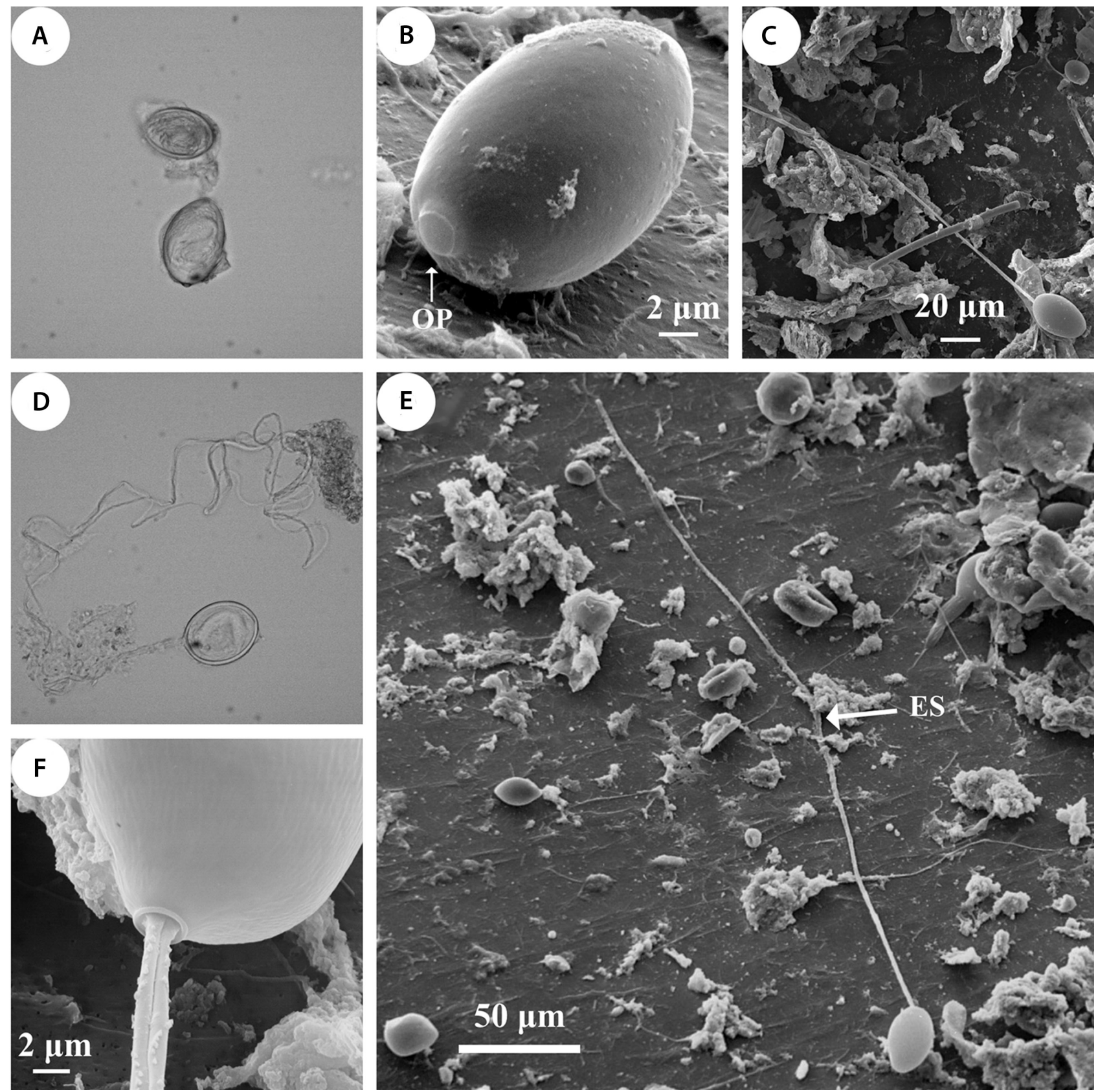

Figure 3. (A) LM image showing two undischarged macrobasic mastigophores isolated from Millepora alcicornis, magnification $400 \mathrm{x}$. (B) SEM image of an undischarged macrobasic mastigophore isolated from M. complanata, showing the operculum (OP). (C) SEM image of a discharged macrobasic mastigophore isolated from M. complanata. (D) LM image of a discharged macrobasic mastigophore of M. complanata, magnification $400 \mathrm{x}$. (E) SEM image of a discharged macrobasic mastigophore isolated from M. alcicornis showing the everted tubule completely extended; the everted shaft $(E S)$ is located at the middle of the tubule. (F) SEM image of a discharged macrobasic mastigophore of M. alcicornis showing the spines of the everted tubule.

dichotoma and M. platyphylla, also present this type of nematocyst in a greater proportion than stenoteles. Although it has been reported that macrobasic mastigophores as well as stenoteles are capable of penetrating the human skin, the results obtained in the present study suggest that the characteristic toxicity of the fire corals is mainly caused by the toxins contained in the macrobasic mastigophores, especially if one considers that other hydroids that contain stenoteles are not toxic to humans $(1,7)$. 

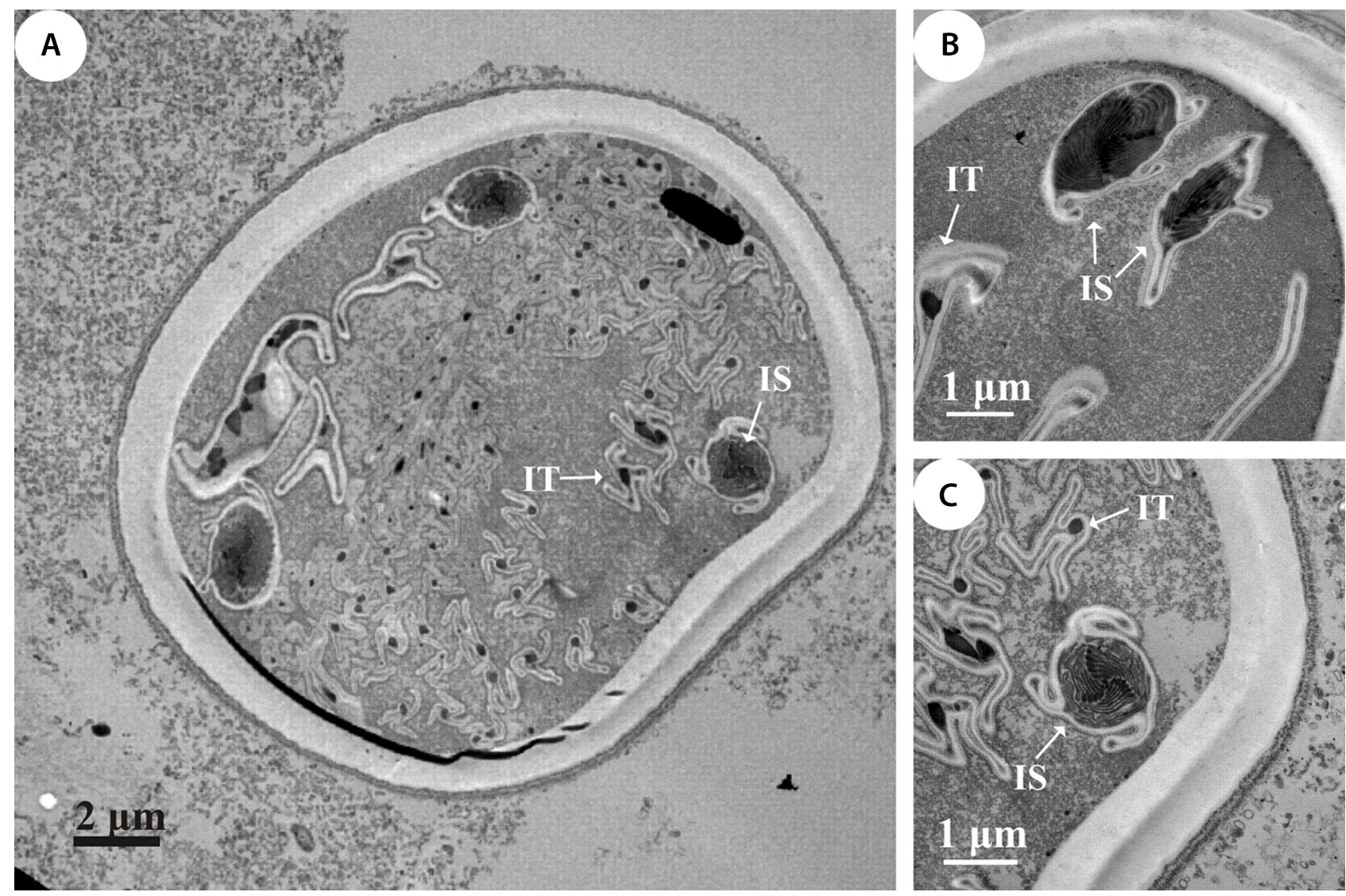

Figure 4. TEM images of undischarged macrobasic mastigophores isolated from Millepora alcicornis. (A) Transversal section showing portions of the inverted shaft (IS) and the inverted tubule (IT). (B) Detail of the inverted shaft showing the tripartite symmetry. (C) Detail showing the thickness of capsule.

\section{ACKNOWLEDGEMENTS}

Alejandro García-Arredondo acknowledges a scholarship from CONACYT. The authors thank: Claudia Moreira and Florencia Colombo (Unidad Académica Puerto Morelos, Instituto de Ciencias del Mar y Limnología, UNAM) for collection of $M$. complanata and M. alcicornis specimens; Francisco Pasos Nájera (Departamento de Fisiología Celular y Tisular, UNAM) for his assistance in the SEM studies; Reynaldo Pless, Ph.D. for valuable suggestions during the process of writing the paper; and Edgar P. Heimer de la Cotera (Instituto de Neurobiología, UNAM) for his valuable comments and ideas.

\section{COPYRIGHT}

(C) CEVAP 2012

\section{SUBMISSION STATUS}

Received: August 12, 2011.

Accepted: November 3, 2011.

Abstract published online: November 28, 2011. Full paper published online: February 28, 2012.

\section{CONFLICTS OF INTEREST}

The authors declare no conflicts of interest.

\section{FINANCIAL SOURCE}

This work was supported by grant CB-200901 (project 133785) to Alejandra Rojas from the Consejo Nacional de Ciencia y Tecnología (CONACYT).

\section{ETHICS COMMITTEE APPROVAL}

The present research was conducted according to and with the approval of the National Commission of Aquaculture and Fishing, The Secretary of Agriculture, Livestock, Rural Development, Fishing and Feeding of Mexican Federal Government (permission number DGOPA.04609.120508.1123).

\section{CORRESPONDENCE TO}

Alejandro García Arredondo, Laboratorio de Investigación Química y Farmacológica de Productos Naturales, Facultad de Química, Universidad Autónoma de Querétaro, Centro 
Universitario, Cerro de las Campanas, Col. Centro, 76010, Querétaro, Qro., México. Phone: +52 442 1921200, ext.5527. Email: alejandro.gr@ uaq.mx.

\section{REFERENCES}

1. Sagi A, Rosenberg L, Ben-Meir P, Hauben DJ. The "fire coral" (Millepora dichotoma) as a cause of burns: a case report. Burns Incl Therm Inj. 1987;13(4):325-6.

2. Bianchini G, Lotti T, Campolmi P, Casigliani R, Panconesi E. Coral ulcer as a vasculitis. Int J Dermatol. 1988;27(7):506-7.

3. Prasad R, Vincent L, Hamilton R, Lim K. Minimal change disease in association with fire coral (Millepora species) exposure. Am J Kidney Dis. 2005;47(1):e15-6.

4. Tardent P. The cnidarian cnidocyte, a high-tech cellular weaponry. Bioessays 1995;17(4):351-62.

5. Wittle LW, Middlebrook R, Lane C. Isolation and partial purification of a toxin from Millepora alcicornis. Toxicon. 1971;9(4):327-31.

6. Middlebrook RE, Wittle LW, Scura ED, Lane CE. Isolation and partial purification of a toxin from Millepora dichotoma. Toxicon. 1971;9(4):333-6.

7. Wittle LW, TScura ED, Middlebrook RE. Stinging coral (Millepora tenera) toxin: a comparison of the crude extracts with isolated nematocyst extracts. Toxicon. 1974;12(5):481-6.

8. Wittle LW, Wheller CA. Toxic and immunological properties of stinging coral toxin. Toxicon. 1974;12(5):1487-93.

9. Radwan FFY. Comparative toxinological and immunological studies on the nematocyst venoms of the Red Sea fire corals Millepora dichotoma and $M$. platyphylla. Comp Biochem Physiol C Pharmacol. 2002;131(3):323-34.

10. Ibarra-Alvarado C, Alejandro García J, Aguilar MB, Rojas A, Falcón A, Heimer de la Cotera EP. Biochemical and pharmacological characterizations obtained from the fire coral Millepora complanata. Comp Biochem Physiol C Toxicol Pharmacol. 2007;146(4):511-8.

11. Meier S, Jensen PR, Adamczyk P, Bächinger HP, Holstein TW, Engel J, et al. Sequence-structure and structure-function analysis in cysteine-rich domains forming the ultrastable nematocyst wall. J Mol Biol. 2007;368(3):718-28.
12. Weber J. Poly $(\gamma$-glutamic acid)s are the major constituents of nematocysts in hydra (Hydrozoa, Cnidaria). J Biol Chem. 1990;265(17):9664-9.

13. Anderson PA, Bouchard C. Regulation of cnidocyte discharge. Toxicon. 2009;54(8):1046-53.

14. Holstein T, Tardent P. An ultrahigh-speed analysis of exocytosis: nematocyst discharge. Science. 1984;223(4638):830-3.

15. Mariscal RN. Nematocysts. In: Muscatine L, Lenhoff HM, (editors). Coelenterate biology: Reviews and new perspectives. Academic Press: New York and other cities; 1974. p. 129-78.

16. Weill, R. Contribution a létude des cnidaires et de leurs nématocystes I. Recherches sur les nématocystes. Trav Stn Zool Wimereux. 1934;10:1-347.

17. Weill R. Contribution a l'étude des cnidaires et de leurs nématocystes II. Valeur taxonomique du cnidome. Trav Sta Zool Wimereux. 1934;11:348-700.

18. Östman C. A guideline to nematocyst nomenclature and classification, and some notes on the systematic value of nematocysts. Sci Mar. 2000;64(1):31-46.

19. Cutress CE. An interpretation of the structure and distribution of Cnidae in Anthozoa. Syst Zool. 1955;3(4):120-37.

20. Östman C, Aquirre A, Mydral M, Nyvall P, Lindström J, Bjöklund M. Nematocysts in Tubularia larynx (Cnidaria, Hydrozoa) from Scandinavia and the northern coast of Spain. Sci Mar. 1995;59(2):165-79.

21. Lewis JB. Biology and ecology of the hydrocoral Millepora on coral reefs. Adv Mar Biol. 2006;50:1-55.

22. Calder DR. Shallow-water hydroids of Bermuda: The Athecate. Roy Ontario Mus Life Sci Contrib. 1988;148:1-107.

23. Grajales A, Sánchez JA. Discharged nematocysts of Millepora alcicornis. Coral Reefs. 2006;25(4):671.

24. Özbek S, Pokidysheva E, Schwager M, Schulthess T, Tariq N, Barth D, et al. The glycoprotein NOWA and minicollagens are part of a disulfide-linked polymer that forms the cnidarian nematocyst wall. J Biol Chem. 2004;279(50):52016-23. 